Review

\title{
Geriatric epidural haematoma:case report and review of the literature
}

*Ersoy Kocabıçak, Cengiz Çokluk, Keramettin Aydın,

Department of Neurosurgery, Medical Faculty, Ondokuz Mayıs University, Samsun, Turkey

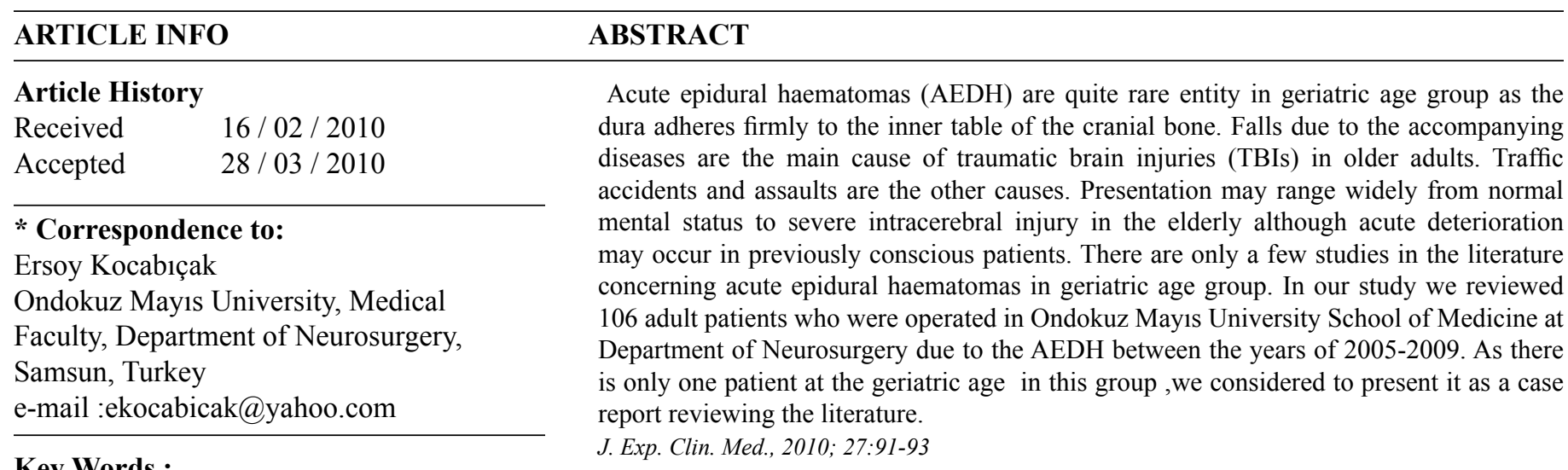

Key Words :

Acute Epidural Haematoma

Bilaterally

Geriatric Age

Assault

Traumatic Brain Injury

Caniotomy

C 2010 OMU All rights reserved

\section{Introduction}

The world's population is getting older. By the year 2020, $20 \%$ of the population will be regarded as elderly. This trend is likely to continue (Le Roux and Nadvi, 2007).

TBI is a significant problem in older adults. Older age is known to negatively influence outcome after TBI (Hukkelhoven et al., 2003; Thompson et al., 2006).

Acute epidural haematomas (AEDH) occur in 1 to $9 \%$ of all head injuries, but it rarely occurs as a result of a head injury in older patients, due to the fact that the dura strongly adheres to the inner table of the cranial bone (Wester, 1999; Hamlat et al., 2005). To the best of our knowledge, there are a few studies in the literature dedicated to the study of AEDH in the elderly.In our study we reviewed 106 adult patients who were operated in Ondokuz Mayıs University School of Medicine at Department of Neurosurgery due to the AEDH between the years of 2005-2009. As there is only one patient at the geriatric age in this group, we considered to present it as a case report reviewing the literature.

\section{Case Report}

A 73 year old male patient was admitted to the emergency room with the complaints of headache, nausea, vomiting and tendency to sleeping.He had a history of being beaten by a group of youngsters 3 hours ago.He didn't have any spesific history besides this.At physical examination, he had a periorbital edema,ecchimosis and an area of 3 centimeter wide maceration on the right frontotemporal region. At neurological examination, he was conscious,

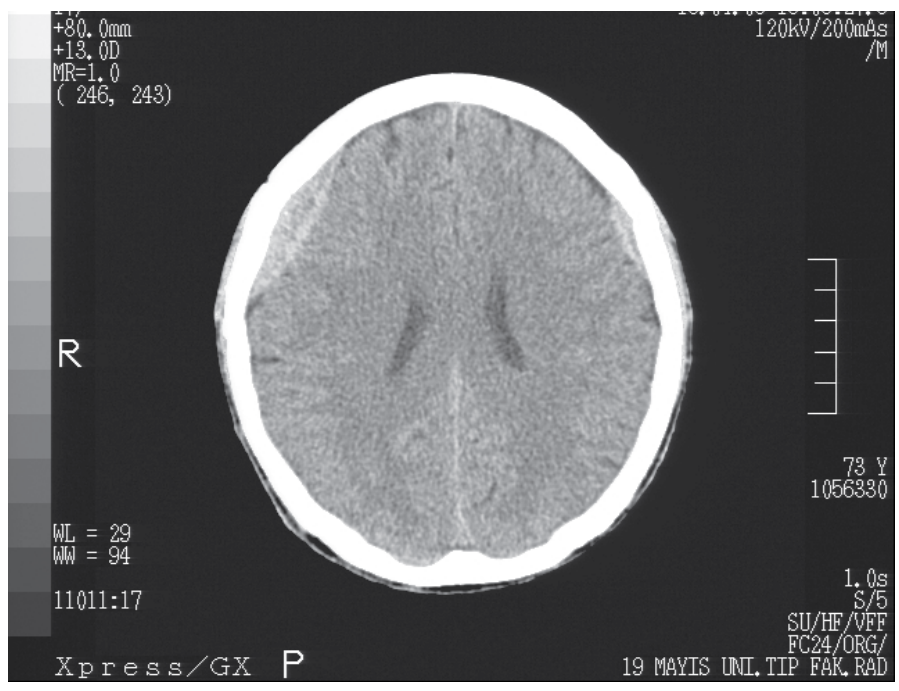

Fig. 1: Preoperative CT:A 12 milimeter wide hyperdense acute epidural haematoma is seen at the right frontotemporal region and there is also another milimetric acute epidural haematoma at the left frontotemporal region 
orientated-cooperated,moderately prone to sleeping and agitated.His pupils were isochoric and didn't have facial asimetry.He had no sign of lateralisation. Glasgow Coma Score (GCS) was 14. Other system examinations didn't show any abnormality.

Cranial Computerized Tomography (CT) showed $\mathrm{AEDH}$ at the right frontotemporal region without causing midline shift.There was also a milimetric AEDH at the right frontotemporal region too (Fig. 1).

The patient was operated.A right frontotemporal craniotomy was accomplished.AEDH was drained. Postoperatively his GCS was 15 and he was discharged with recommendations (Fig. 2).

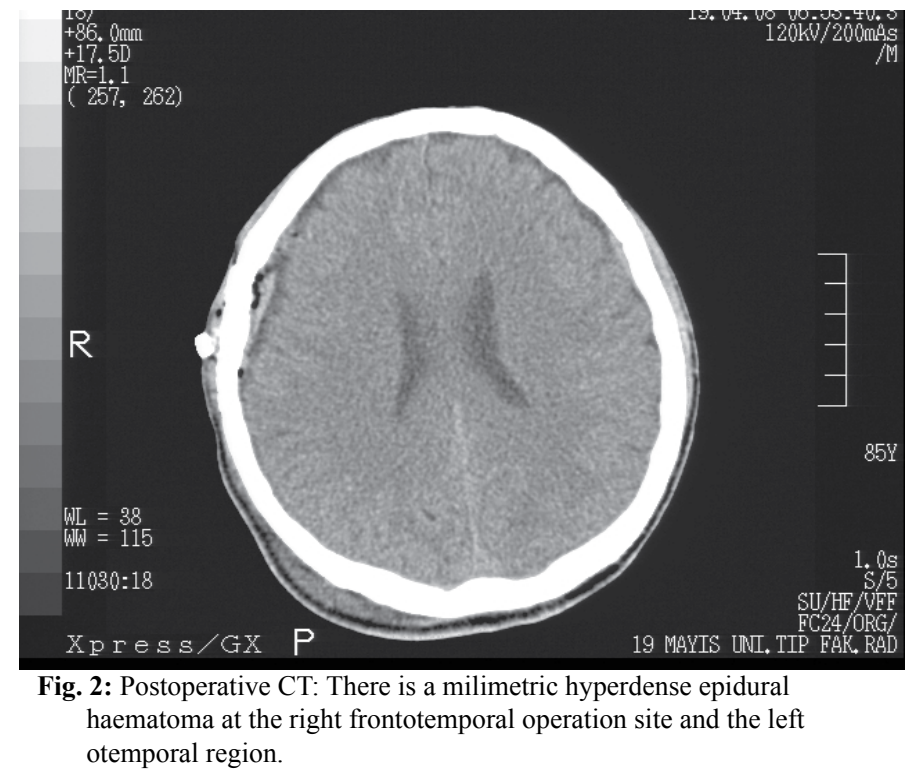

\section{Discussion}

AEDH can result from injury to the middle meningeal artery, the middle meningeal vein, the diploic veins, or the venous sinuses. Historically, bleeding from the middle meningeal artery has been considered the main source for AEDH (Bullock et al., 2006). Falls are the leading cause of TBI for older adults (51\%), and motor vehicle traffic crashes are second (9\%). Assaults acount for $1 \%$ of TBIs in older adults, and all other known causes account for $17 \%$ ,although more than $21 \%$ of TBIs in older adults are from unknown causes( Thompson et al., 2006). Assault was the cause of AEDH in our patient. GCS, age, pupillary abnormalities, associated intracranial lesions, time between neurological deterioration and surgery, and intracranial pressure (ICP) have been identified as important factors determining outcome from AEDH ( Bullock et al., 2006).

AEDH in the elderly is rare. There are only a few studies involving AEDH in geriatric age group. In Amacher and Bybee's series of 56 head-injured elderly patients, none had an AEDH. In a series of 136 consecutive elderly patients with acute head injury, only two were found to harbour AEDH. The rarity of AEDH in the elderly is probably due to the increasing adherence of the dura mater to the skull with advancing age and due to the elderly being less exposed to risk taking behaviour (Le Roux and Nadvi, 2007). Hamlat et al. (2005) studied 500 patients with AEDH confirmed by CT scan. 14 of these patients were aged over 70 . In the other study Le Roux et al. (2007) performed, only 32 patients of geriatric age in 3249 cases with AEDH were reported.

Presentation may range widely from normal mental status to severe intracerebral injury in the elderly although acute deterioration may occur in previously conscious patients (Hamlat et al., 2005). Falls are the main cause of head traumas in the elderly due to the accompanying diseases whereas traffic accidents are the main cause in the other age groups(Amacher and Bybee , 1987; Cagetti et al., 1992; Nagurney et al., 1998; Grant et al., 2000). Therefore, the factors that may explain the good prognosis observed in the elderly are the trauma mechanism and compensatory intracranial behaviour. (Hukkelhoven et al., 2003; Bullock et al., 2006).

In surgical series, EDH are more frequently located in the temporoparietal and temporal regions as compared with other locations. In 2 to $5 \%$ of patients, bilateral EDH are found and there seems to be a slight predominance of right- sided EDH over left-sided lesions (Bullock et al., 2006). In the elderly, most AEDH cases developed in the parietal region, unlike younger patients (Wester, 1999; Thompson et al., 2006). This site of predilection can be attributed to the fact that, with increasing age, the dura mater is more loosely attached to the inner table of the parietal bone than elsewhere in the calvarium, and it is therefore more easily detached on impact (Hamlat et al., 2005). In our patient AEDH was bilaterally and frontotemporal regions were the site of involvement.

\section{REFERENCES}

Amacher A.L., Bybee D.E., 1987. Toleration of head injury by the elderly. Neurosurgery. 20, 954-958.

Bricolo A.P., Pasut L.M., 1984 .Extradural hematoma: toward zero mortality. A prospective study. Neurosurgery. 14, 8-12.

Bullock M.R., Chesnut R., Ghajar J., Gordon D., Hartl R., Newell D.W., Servadei F., Walters B.C., Wilberger J.E., 2006. Surgical Management of Traumatic Brain Injury Author Group. Surgical management of acute epidural hematomas. Neurosurgery. 58, 7-15.

Cagetti B., Cossu M., Pau A., Rivano C., Viale G., 1992. The outcome from acute subdural and epidural intracranial haematomas in very elderly patients. Br. J. Neurosurg. 6, 227- 231.

Cordobés F., Lobato R.D., Rivas J.J., Muñoz M.J., Chillón D., Portillo J.M., Lamas E., 1981.Observations on 82 patients with extradural hematoma. Comparison of results before and after the advent of computerized tomography. J. Neurosurg. 54, 179-186. 
Grant P.T., Henry J.M., McNaughton G.W., 2000.The management of elderly blunt trauma victims in Scotland: evidence of ageism? Injury. 31, 519-528.

Hamlat A., Mazzon A., Adn M., Morandi X., Riffaud L., Guegan Y., Brassier G., 2005. Intracranial epidural haematomas in elderly patients: observations in 14 patients. Acta Neurochir (Wien). 147, 1055-1060.

Hukkelhoven C.W, Steyerberg E.W., Rampen A.J., Farace E., Habbema J.D., Marshall L.F., Murray G.D., Maas A.I., 2003. Patient age and outcome following severe traumatic brain injury: an analysis of 5600 patients. J. Neurosurg. 99, 666-673.

Le Roux A. A., Nadvi S. S., 2007. Acute extradural haematoma in the elderly Brit. J. Neurosurg., 21,16-20

Nagurney J.T., Borczuk P., Thomas S.H., 1998. Elderly patients with closed head trauma after a fall: mechanisms and outcomes. J. Emerg. Med. 16, 709-713.

Thompson H.J., McCormick W.C., Kagan S.H., 2006. Traumatic brain injury in older adults: epidemiology, outcomes, and future implications. J. Am. Geriatr. Soc. 54, 1590-1595.

Wester K., 1999. Decompressive surgery for "pure" epidural hematomas: does neurosurgical expertise improve the outcome? Neurosurgery. 44, 495-500. 